Ross River virus and Barmah Forest virus. Med J Aust 1998; 169: 159-163.

10. Communicable Diseases Surveillance and Control Unit. Notifiable Disease Manual. Sydney: NSW Department of Health, 2002.

11. MapInfo Professional Version 7.0. MapInfo Australia.

12. Muscatello D, McAnulty J. Arboviruses in NSW 1991 to 1999. N S W Public Health Bull 11(11): 190-192.

13. Australian Government Department of Health and Ageing. National Notifiable Diseases Surveillance System. Available at www.cda.gov.au/surveil (accessed 19 February 2004).

14. Vale TG, Carter I, McPhie, James GS, Cloonan J. Human arbovirus infections along the south coast of New South Wales. Aust J Exp Biol Med Sci 1986; 64: 307-309.

15. Hawkes RA, Clement RB, Naim HM, Myrick BA, Ramsay LG. Barmah Forest virus infections in humans in New South Wales. Med J Aust 1987; 146(11): 569-573.
16. Boyd AM, Kay BH. Vector competence of Aedes aegypti, Culex sitiens, Culex annulirostris and Culex quinquefasciatus for Barmah Forest virus. J Med Entomol 1999; 36(4): 508-514.

17. Vale TG, Spratt DM, Cloonan MJ. Serological evidence of arbovirus infection in native and domesticated mammals on the south coast of New South Wales. Aust J Zool 1991; 39: 1-7.

18. Boyd AM, Hall RA, Gemmell RT, Kat BH. Experimental infection of Australian brushtail possums, Trichosurus (Phalangeridae: Marsupialia), with Ross River and Barmah Forest viruses by use of natural mosquito vector system. Am J Trop Med Hyg 2001; 65(6): 777-782.

19. Aldred J, Campbell J, Mitchell G, Davis G, Elliott J. Involvement of wildlife in the natural cycle of Ross River and Barmah Forest viruses. Proceedings from Wildlife Diseases Association Meeting 1991 (unpublished).

20. Russell R. Arboviruses and their vectors in Australia: an update on the ecology and epidemiology of some mosquito borne arboviruses. Rev Med Vet Entomol 1995; 83(4): 141-143. Fit

\title{
THE INCREASE IN PRESENTATIONS OF DENGUE FEVER IN NEW SOUTH WALES
}

\section{Linda Hueston}

Centre for Infectious Diseases and Microbiology Institute of Clinical Pathology and Medical Research, Westmead

\section{BACKGROUND}

The earliest known reports of dengue fever, a mosquitoborne disease, are from China in 992 AD.${ }^{1}$ During the 18 th and 19th centuries, both the slave trade and increases in shipping and commercial trade saw the disease spread throughout the world via sailing ships. ${ }^{1,2}$ This spread was largely due to the water supplies stored on board ships, which provided an effective means of travel for the virus and vector that cause dengue fever.

The earliest record of dengue fever in Australia is 1873, when 8 cases occurred in Sydney, imported from a ship from Mauritius. ${ }^{3}$ The last epidemic in New South Wales was between 1942 and 1944, and is attributed to troop movements by steam train. ${ }^{4}$ While epidemics of dengue fever have been documented in Queensland, New South Wales, Western Australia and the Northern Territory, it is unlikely that dengue fever has remained endemic between these epidemics. ${ }^{5}$ It is more likely that dengue fever was, and continues to be, reintroduced by tourists or residents returning from overseas countries where dengue fever is endemic. ${ }^{4,6}$ Since 1944 , epidemics have been confined to those areas of Queensland that correspond to the geographic range of the vector mosquito Aedes aegypti. ${ }^{7}$
This confinement may be due to the introduction of reticulated water supplies and the reduction of breeding sites, the combined effect of which has seen the reduction and eradication of the vector mosquito in some areas. ${ }^{4}$ Since 1944, all cases of dengue fever in New South Wales but one have been acquired in Queensland or overseas. The one exception was an infection acquired by a biomedical engineer working with live viruses in the production of diagnostic kits.

In 1991 dengue fever became a notifiable disease in New South Wales. Since then all new laboratory notifications are entered into the NSW Notifiable Diseases Database (NDD), maintained by the Communicable Diseases Branch, NSW Department of Health, and are accessed through the Graphical Online Data Surveillance Evaluation for Notifiable Diseases (GODSEND), maintained by the Centre for Epidemiology and Research, NSW Department of Health. A review of the NDD has shown an increase in the number of notifications of dengue fever over the last 5 years. The Arbovirus and Emerging Diseases Unit, Centre for Infectious Diseases and Microbiology, Institute of Clinical Pathology and Medical Research (Westmead), undertakes a large proportion of dengue virus testing for New South Wales. We have noticed an increase in requests for dengue serology and also an increase in the number of positive notifications between 1999 and 2003. This article describes the pattern of requests and the clinical and travel histories of cases notified through our laboratory, and discusses how these findings relate to the apparent 
increase in notifications of dengue fever in New South Wales.

\section{METHODS}

In New South Wales, a case of dengue fever is defined according to national guidelines. ${ }^{8}$ The majority of notifications of dengue fever are serologically determined, usually on the basis of a single IgM positive result.

Our laboratory defines a primary case of dengue fever as one in which $\operatorname{IgG}$ and $\operatorname{IgM}$ are negative on acute phase samples but positive on the convalescent phase sample. Alternatively, a primary case can be defined where IgG is negative, IgM is positive on an acute phase sample and where there is evidence of $\mathrm{IgG}$ seroconversion in the convalescent phase sample. We define a secondary case of dengue fever as one where $\operatorname{IgG}$ is positive but $\operatorname{IgM}$ is negative on an acute sample and which demonstrates a fourfold or greater rise in IgG titre with or without the presence of IgM. In addition to the serology findings, the case must have a consistent clinical and travel history.

Our interest in the reasons for the increase in both requests for serology and dengue fever infections led us to develop a questionnaire to obtain more information on notified cases from the physician they attended for treatment.

\section{RESULTS}

Figure 1 shows the increasing trend in notifications of dengue fever reported to NSW Health between 1999 and 2003. ${ }^{9}$ This figure does not include secondary infections without IgM or unspecified flavivirus infections (most of which would be dengue, based on travel and clinical history) reported to the NDD. The data may therefore represent an underestimate of case numbers.

Our laboratory has noted a 30 per cent increase in the number of requests for dengue serology over the last 5 years (Table 1).

In 2003, we diagnosed 111 cases of primary dengue fever. In 1999 and 2000 only primary infections were diagnosed. In 2001 we began to see cases of secondary infection ( 1 case), in 2002 there were 2 cases of secondary infection, and in 2003 there were 9 cases.

In a follow-up of 100 serology requests that originated in New South Wales, we used the questionnaire for attending physicians shown in Table 2, from which the following information was obtained.

The clinical presentation of dengue fever was broad, ranging from mild flu-like illness through to haemorrhagic symptoms and moderate liver involvement. Most patients presented within 5-7 days of onset. All cases had histories of overseas travel. Destinations included Thailand, Malaysia, Indonesia, Korea, India, Sri Lanka, Timor, the Solomon Islands, Fiji, Vanuatu, Samoa, Tahiti, Noumea and New Caledonia. Only 5 cases were tourists visiting New South Wales from Asia (3 cases from Malaysia) and the Pacific (2 cases from Samoa). The remainder were residents of New South Wales.

General practitioners saw the majority of primary infections. Emergency departments were the next most

\section{FIGURE 1}

NOTIFICATIONS OF DENGUE FEVER, NEW SOUTH WALES, 1999-2003

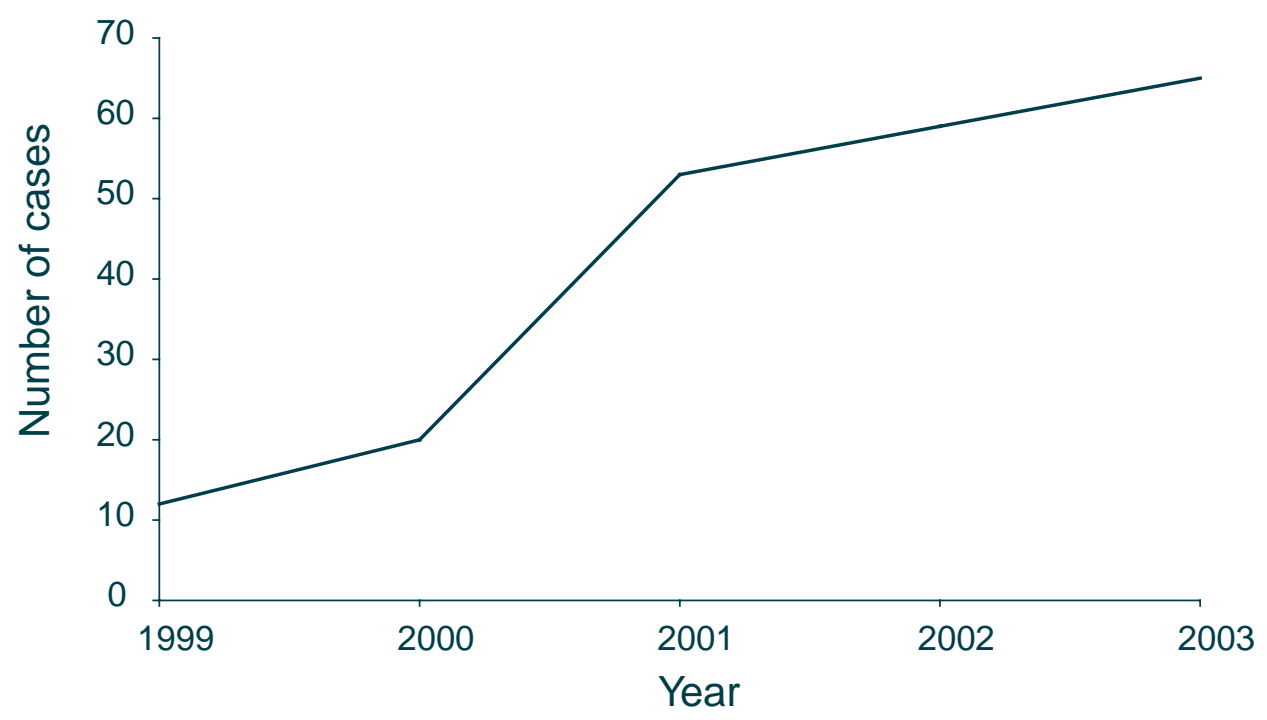

Source: Notifiable Diseases Database, Communicable Diseases Branch, NSW Department of Health, accessed via the Graphical Online Data Surveillance Evaluation for Notifiable Diseases (GODSEND), Centre for Epidemiology and Research, NSW Department of Health. 
TABLE 1

NUMBER OF SEROLOGY REQUESTS AND CASES OF PRIMARY AND SECONDARY INFECTION, DENGUE FEVER, NEW SOUTH WALES, 1999-2003

\begin{tabular}{|ccccc|}
\hline Year & $\begin{array}{c}\text { Serology } \\
\text { requests }\end{array}$ & $\begin{array}{c}\text { Positive } \\
\text { serology }\end{array}$ & $\begin{array}{c}\text { Primary } \\
\text { infection }\end{array}$ & $\begin{array}{c}\text { Secondary } \\
\text { infection }\end{array}$ \\
\hline 1999 & 700 & 67 & 67 & 0 \\
2000 & 800 & 70 & 70 & 0 \\
2001 & 850 & 81 & 80 & 1 \\
2002 & 920 & 90 & 88 & 2 \\
2003 & 1000 & 120 & 111 & 9 \\
\hline
\end{tabular}

Source: Dengue Statistics Database, Arbovirus and Emerging Diseases Unit, Centre for Infectious Diseases and Microbiology, Institute of Clinical Pathology and Medical Research (Westmead).

\section{TABLE 2}

FOLLOW-UP QUESTIONNAIRE FOR PRACTITIONERS, NOTIFICATIONS OF DENGUE FEVER, NEW SOUTH WALES, 1999-2003

What was the clinical picture?

What was the onset date of symptoms?

Has there been any recent travel?

If yes specify places visited and travel dates.

Was the patient seen at an emergency room, medical clinic, or general practice?

Did the patient require hospitalisation? If yes what was the length of stay? Was intensive care required?

Is the patient resident in NSW?

Country of birth. If not Australia what was the patient's age

on arrival in Australia?

Is the patient an overseas visitor?

What was the reason for testing?

Is follow-up testing possible?

Before this case how aware were you of dengue fever as a cause of infection?

Would you like to receive training material on dengue fever diagnosis?

Source: Arbovirus and Emerging Diseases Unit, Centre for Infectious Diseases and Microbiology, Institute of Clinical Pathology and Medical Research (Westmead).

common detection point for primary infections, particularly on weekends and holidays. The secondary infections were seen through emergency departments. Six secondary infections and 3 primary infections spent time as hospital inpatients. The duration of inpatient stay was 2-13 days. All secondary cases were residents who, before moving to Australia, had been born and lived for several years in countries where dengue fever was endemic.

Thirty per cent of laboratory requests included some clinical history, 2 per cent mentioned travel in the history but did not specify the travel destination, and none mentioned the date of onset. Twenty per cent of patients had received information during their overseas travel advising that dengue fever was active in the areas visited and that they should seek medical assistance if on returning home they developed symptoms compatible with dengue fever. The majority of patients were tested because they were clinically ill, although some patients requested testing because their travel companions had been diagnosed overseas. However, one common feature was that dengue fever was not rated highly in the differential diagnosis. Generally, dengue fever was considered after other possibilities were excluded, thereby delaying a diagnosis for up to 5 days.

Malaria was the most commonly suspected cause, followed by influenza, glandular fever and hepatitis. The majority of practitioners and patients were happy to send follow-up blood samples, particularly if it improved the chances of obtaining a definitive diagnosis. It was not always possible to obtain follow-up blood samples on tourists, as they had frequently moved on to their next destination. Seventy per cent of practitioners felt they would benefit from receiving information on overseas areas where dengue fever is considered a problem and information pertaining to diagnosis and treatment.

\section{DISCUSSION}

Dengue fever has become one of the most significant emerging diseases in tropical countries. Worldwide, more than 2.5 billion people are at risk of infection and each year 50-100 million cases of dengue fever are believed to occur. ${ }^{1}$ There are many reasons for this global increase, including: complacency in mosquito control measures; increased population growth and subsequent unplanned urbanisation, leading to increases in breeding sites for the vector mosquito; and susceptible populations for the virus. Increased international trade has provided a rapid means of transport for the vector mosquito to new areas, and has facilitated its reintroduction to areas where it had previously been eradicated. The increase in air travel has provided an ideal mechanism for transporting the virus to new areas via travellers. ${ }^{1,10}$

Data from the Bureau of Tourism Research shows that 47 per cent of tourists enter Australia through Sydney. The number of Australians travelling abroad has also shown a steady increase in the last 5 years. The majority of tourists arrive via Asia and the Pacific, areas that have significant problems with dengue fever. These regions are also among the most popular destinations for Australians. ${ }^{11}$ As our study suggests, it is reasonable to expect that the increase in cases in dengue fever in New South Wales is a result of increasing travel to endemic areas.

Although the numbers in our study are small, it would seem that secondary dengue fever infections are also increasing. This is not surprising because, as the number of primary infections rise, the stage is set for subsequent infections with additional travel. Before moving to 
Australia, many New South Wales residents were born and lived in overseas areas where dengue fever is endemic and may have been previously infected. This immunologic 'priming' increases the risk of the more serious haemorrhagic dengue fever if previously infected people travel to endemic areas in the future.

Dengue fever is a disease that many New South Wales general practitioners and casualty department staff will see in their careers. Our study has shown that among this group there is a low index of suspicion and therefore dengue fever is not always considered in the differential diagnosis. If laboratories are to accurately diagnose infections of dengue fever, the provision of clinical and travel histories is essential to ensure that the correct viral test panels are undertaken and that interpretation of the results is appropriate. This is particularly important in New South Wales where several flaviviruses known to infect humans circulate.

It is important to ensure that cases are followed up to determine that infections were acquired overseas and not locally. Certainly the Queensland experience has shown that diagnostic training for general practitioners and emergency department physicians is an important surveillance tool for dengue fever, in addition to followup by public health authorities. This would provide a window of opportunity for public health practitioners in New South Wales to take a leading role in the provision of training and educational opportunities to the relevant clinical groups. Importantly, our study has also shown an interest in obtaining such information by health care providers.

In recent years, we have seen Aedes aegypti reintroduced into Queensland. There is ample evidence of dengue fever epidemics in Queensland beginning with one traveller 'seeding' the vector mosquito population and subsequently causing locally acquired cases., ${ }^{5,10}$ It has long been assumed that Aedes aegypti had been eradicated from the remainder of Australia. ${ }^{12}$ However, in February this year Aedes aegypti was found in significant numbers in Tennant Creek in the Northern Territory. The vector mosquito status of New South Wales may change in the future, as it has in Queensland and the Northern Territory. Whether this happens or not, dengue fever remains the most common cause of flaviviral disease in New South Wales, and case numbers are increasing. We cannot stop people travelling, but we can improve the index of disease suspicion and diagnosis of disease.

Dengue fever and its vector mosquito have adapted and evolved in such a way as to maximise their opportunities to increase their geographic range. In such a climate, the importance of rapidly and accurately diagnosing imported cases of dengue in tourists or returning residents, and thereby preventing onward transmission, is an important public health role shared by general practitioners, public health officers, and diagnostic and reference laboratories throughout Australia.

\section{REFERENCES}

1. Gubler DJ. Dengue and dengue hemorrhagic fever: Its history and resurgence as a global health problem. Gubler DJ, Kuno $\mathrm{G}$ (editors). Dengue and dengue hemorrhagic fever. Fort Collins, Colorado: CAB International; 1997: 1-22.

2. Gubler DJ. Epidemic dengue-dengue hemorrhagic fever as a public health, social and economic problem in the 21 st century. Trends Microbiol 2002; 10: 100-3.

3. Lumley GF, Taylor FH. Dengue: service publications. Sydney: School of Public Health and Tropical Medicine, University of Sydney, 1943; 1-171.

4. Mackenzie JS, LaBrooy JT, Hueston L, Cunningham AL. Dengue in Australia. J Med Microbiol 1996; 45: 159-61.

5. Kay BH, Barker-Hudson P, Stallman ND, Wiemers MA, Marks EN, Holt PJ, et al. Dengue fever: Reappearance in Northern Queensland after 26 years. Med J Aust 1984; 140: 264-8.

6. Mackenzie JS, Lindsay MD, Coelen RJ, Broom AK, Hall RA, Smith DW. Arboviruses causing human disease in the Australasian zoogeographic region. Arch Virol 1994; 136: 447-67.

7. Sinclair DP. The distribution of Aedes aegypti in Queensland, 1990 to 30 June 1992. Commun Dis Intell 1992; 16: 400-3.

8. Australian National Notifiable Diseases List and Case Definitions. Available at www.health.gov.au/internet/wcms/ publishing.nsf/Content/cda_nndss_dislist.htm.

9. Graphical Online Data Surveillance Evaluation for Notifiable Diseases (GODSEND). Sydney: Centre for Epidemiology and Research, NSW Department of Health, 2004.

10. Hanna J, Ritchie S, Merritt A, van den Hurk A, Phillips DA, Serafin IL, et al. Two contiguous outbreaks of dengue type 2 in North Queensland. Med J Aust 1998; 168: 221-5.

11. Tourism Snapshot: International 1997-2002. Available at www.btr.gov.au.

12. Mackenzie JS, Broom AK, Hall RA, Johansen CA, Lindsay MD, Phillips DA, et al. Arboviruses in the Australian region, 1990 to 1998. Commun Dis Intell 1998; 22: 93-100. Wt 